\title{
Pre-eclampsia associated bilateral serous retinal detachment
}

\author{
Sreeram Jayaraj, Ramanuj Samanta (D) ,Athul Suresh Puthalath (D) , \\ Kavya Subramanian
}

Ophthalmology, All India Institute of Medical Sciences, Rishikesh, India

\section{Correspondence to} Dr Ramanuj Samanta; ramanuj.samanta@gmail.com

Accepted 2 September 2020

Check for updates

(c) BMJ Publishing Group Limited 2020. No commercial re-use. See rights and permissions. Published by BMJ.

To cite: Jayaraj S, Samanta $R_{\text {, }}$ Puthalath AS, et al. BMJ

Case Rep 2020:13:e238358.

doi:10.1136/bcr-2020-

238358

\section{DESCRIPTION}

A 29-year-old woman was referred to ophthalmology emergency with bilateral sudden diminution of vision, noticed 4 hours following caesarean section. Ocular examination revealed visual acuity of finger counting at 2-feet distance in both eyes. Intraocular pressure and anterior segment were unremarkable. Dilated fundus examination (figure 1A,B) revealed bilateral serous retinal detachment (SRD) involving macula. There was no associated retinal haemorrhages, exudates, cottonwool spots, disc oedema, vitritis or choroiditis lesion. Optical coherence tomography (OCT) of both eyes (figure 1C,D) showed massive subretinal fluid (SRF). General evaluation revealed facial puffiness (figure 1E) and bilateral pedal oedema (figure 1F) suggestive of anasarca. Measured blood pressure (BP) at the time of ocular evaluation was $130 / 80 \mathrm{~mm} \mathrm{Hg}$

Review of hospital records revealed that she was admitted to the Department of Obstetrics and Gynaecology with twin pregnancy at 37 weeks of gestation (gravida 2, para 1) with high BP $(162 / 102 \mathrm{~mm} \mathrm{Hg})$ on repeated measurements, headache, facial puffiness and pedal oedema. Her laboratory evaluation including complete haemogram, renal function test, liver function test and serum electrolytes were unremarkable except for serum albumin $(2.4 \mathrm{mg} / \mathrm{dL})$. Urine examination revealed $2+$ proteinuria. Considering a diagnosis of severe pre-eclampsia, treatment with magnesium sulfate was initiated according to Pritchard regimen. ${ }^{12} \mathrm{~A}$ loading dose of $14 \mathrm{~g}$ (4g intravenous and $10 \mathrm{~g}$ intramuscular), followed by a maintenance dose of $5 \mathrm{~g}$ every 4 hourly in alternate buttocks was given. She underwent caesarean section subsequently.

Based on her recent obstetrical records and ophthalmic features, an ocular diagnosis of severe pre-eclampsia associated bilateral SRD was made. The maintenance dose of magnesium sulfate was continued until 24 hours postoperatively. She was also given diuretics and intravenous albumin infusion for 3 consecutive days. Four weeks following caesarean section, her best-corrected visual acuity improved to 20/30 in both eyes with complete resolution of SRD (figure 1G,H) and disappearance of SRF on OCT (figure 1I,J). Clinical examination revealed normal BP, resolution of facial puffiness (figure $1 \mathrm{~K}$ ) and pedal oedema (figure $1 \mathrm{~L}$ ). Repeat laboratory evaluation yielded normal results.

Pre-eclampsia affects about $3 \%-5 \%$ of pregnancies. It is defined as new-onset hypertension after 20 weeks of gestation, associated with proteinuria and other maternal organ dysfunctions (renal/ hepatic/neurological/haematological/uteroplacental or fetal growth restriction). ${ }^{3}$ Visual symptoms may be seen in up to $25 \%$ of pre-eclamptic patients although SRD may occur in around 1\% of severely affected individuals only. Both antepartum and postpartum SRD have been described in the literature. ${ }^{4}$ Persistent placental ischaemia and oxidative stress in pre-eclampsia cause generalised endothelial dysfunction and vasospasm, which affects the choroidal vasculature also. This results in fibrinoid necrosis of choroidal vessels and occlusion of the choriocapillaris, which subsequently compromises fluid transport by retinal pigment epithelium (RPE) leading to SRD. ${ }^{5}$ Choroidal circulation is more prone to pre-eclampsia induced hypertensive changes as compared with retinal circulation due to multiple reasons. Choroidal arteries have lesser branches and supply the choriocapillaris in shorter right-angled course, thus directly transmitting the high BP to choriocapillaris. ${ }^{6}$ Moreover, the choroidal vasculature is devoid of autoregulation and controlled by sympathetic nervous system, making them further prone. Whether presence of SRD in pre-eclamptic patient has additional risk on mother or fetus is debated. ${ }^{4}$ The mainstay of management of pre-eclampsia is early detection, control of BP and delivery before irreversible complication sets in. ${ }^{3}$ Ophthalmic management of pre-eclampsia associated SRD is conservative and spontaneous resolution generally occurs in

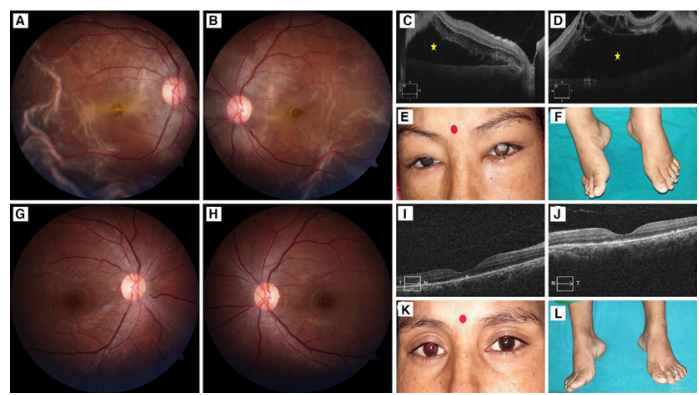

Figure 1 Fundus photograph $(A, B)$ at presentation showed bilateral serous retinal detachment (SRD) and marked subretinal fluid (SRF) on optical coherence tomography $(\mathrm{OCT})(\mathrm{C}, \mathrm{D}$; yellow star mark). Clinical evaluation revealed facial puffiness and white pupillary reflex due to SRD (E) and bilateral pedal oedema (F). Repeat fundus photograph 4 weeks following caesarean section showed resolution of $\operatorname{SRD}(\mathrm{G}, \mathrm{H})$ and disappearance of SRF on OCT $(\mathrm{I}, \mathrm{J})$. Features of anasarca also receded $(K, L)$. 
few weeks with good visual recovery to predetachment level. ${ }^{7}$ Poor outcome may be associated with concurrent presence of retinopathy, macular involvement of SRD and extensive RPE necrosis. ${ }^{57}$ The obstetricians should be cognizant to investigate vision abnormalities in the setting of pre-eclampsia and refer to the ophthalmologists for further detailed evaluation.

\section{Patient's perspective}

I noticed marked decline in vision in both of my eyes following childbirth. I was evaluated by a team of doctors including eye specialist and was reassured that my vision is likely to improve spontaneously without any active eye treatment. Although I was apprehensive initially, I regained my vision completely in a month. Now, my eyesight is perfectly fine and my blood pressure is also normal.

\section{Learning points}

- Pre-eclampsia associated serous retinal detachment (SRD) may lead to significant visual morbidity and can present in postpartum period also.

- Pre-eclamptic choroidopathy (manifesting as SRD) may be seen without concomitant features of retinopathy (retinal haemorrhages, hard exudates, cotton-wool spot).

- SRD usually resolves spontaneously following management of pre-eclampsia without any active ocular intervention; favourable visual recovery is seen in most cases.
Acknowledgements We thank Dr Anoosha Ravi and the Department of Obstetrics and Gynaecology of the Institute for their contribution.

Contributors SJ: data acquisition, data analysis, drafting of manuscript and approval of final version of manuscript. RS: conception and design of study, data interpretation, drafting and critical revision of manuscript and approval of final version of manuscript. ASP: design of study, data interpretation, drafting of manuscript and approval of final version of manuscript. KS: data acquisition, drafting of manuscript and approval of final version of manuscript.

Funding The authors have not declared a specific grant for this research from any funding agency in the public, commercial or not-for-profit sectors.

Competing interests None declared.

Patient consent for publication Obtained.

Provenance and peer review Not commissioned; externally peer reviewed.

\section{ORCID iDs}

Ramanuj Samanta http://orcid.org/0000-0002-9737-8346

Athul Suresh Puthalath http://orcid.org/0000-0002-0483-7014

\section{REFERENCES}

1 American College of Obstetricians and Gynecologists, Task Force on Hypertension in Pregnancy. Hypertension in pregnancy. Report of the American College of Obstetricians and Gynecologists' Task Force on Hypertension in Pregnancy. Obstet Gynecol 2013:122:1122-31.

2 Pritchard JA, Cunningham FG, Pritchard SA. The Parkland Memorial Hospital protocol for treatment of eclampsia: evaluation of 245 cases. Am J Obstet Gynecol 1984; 148:951-63.

3 Mol BWJ, Roberts CT, Thangaratinam S, et al. Pre-Eclampsia. Lancet 2016;387:999-1011.

4 Abu Samra K. The eye and visual system in the preeclampsia/eclampsia syndrome: what to expect? Saudi J Ophthalmol 2013;27:51-3.

5 Lee CS, Choi EY, Lee M, et al. Serous retinal detachment in preeclampsia and malignant hypertension. Eye 2019;33:1707-14.

6 Hayreh SS. Vascular pattern of the choriocapillaris. Exp Eye Res 1974;19:101-4.

7 Jaffe G, Schatz H. Ocular manifestations of preeclampsia. Am J Ophthalmol 1987;103:309-15

Twitter Athul Suresh Puthalath @asputhalath

Copyright 2020 BMJ Publishing Group. All rights reserved. For permission to reuse any of this content visit

https://www.bmj.com/company/products-services/rights-and-licensing/permissions/

BMJ Case Report Fellows may re-use this article for personal use and teaching without any further permission.

Become a Fellow of BMJ Case Reports today and you can:

- Submit as many cases as you like

- Enjoy fast sympathetic peer review and rapid publication of accepted articles

- Access all the published articles

- Re-use any of the published material for personal use and teaching without further permission

Customer Service

If you have any further queries about your subscription, please contact our customer services team on +44 (0) 2071111105 or via email at support@bmj.com.

Visit casereports.bmj.com for more articles like this and to become a Fellow 